\title{
MESHING STRATEGI UNTUK MEMPREDIKSI HAMBATAN TOTAL PADA KAPAL PLANING HULL
}

\author{
Abubakar Fathuddiin \\ Mahasiswa \\ Universitas Diponegoro \\ Departemen Teknik Perkapalan
}

Samuel

Tenaga Pengajar (Dosen) Universitas Diponegoro Departemen Teknik Perkapalan Email: samuel@ft.undip.ac.id
A high-speed vessel has a range of Froude Number $(\mathrm{Fr})>1$. A drag prediction method based on $\mathrm{Fr}>1$ has high complexity because it is influenced by trim and heave motions. Hence, a specific treatment is necessary to obtain accurate results. This study is using mesh density and mesh shapes to predict the total drag of a planing hull ship. The Computational Fluid Dynamic (CFD) results show good performance in predicting the drag, trim, and heave. Mesh density of $2300 K$ shows the most stabilized result. The trimmed mesh type is more efficient to obtain accurate results because it has a smaller mesh size. The polyhedral mesh type is as good as trimmed mesh but is not as efficient as trimmed mesh and it has largely a timeconsuming time.

Keywords: Planing Hull, CFD, Mesh

\section{PENDAHULUAN}

Metode komputasi numerik / Computational Fluid Dynamic (CFD) merupakan metode yang banyak digunakan saat ini untuk memprediksi interaksi suatu objek dengan fluida. Hal tersebut dikarenakan komputasi numerik memiliki kemampuan untuk memodifikasi model kapal yang cukup baik dibanding dengan pendekatan analitik. Ada 2 cara untuk memastikan data hasil komputasi numerik benar atau valid. Pertama yaitu dengan membandingkan dengan hasil eksperimen sehingga dapat diketahui nilai error yang terjadi. Kemudian yang kedua yaitu membandingkan beberapa ukuran mesh hingga tidak terjadi perbedaan hasil yang signifikan (dependent). Beberapa studi sebelumnya yang menggunakan cara ini yaitu [1] dengan membandingkan mesh dengan $650 \mathrm{~K}$ (coarse mesh), 900K (medium mesh) dan $1270 \mathrm{~K}$ (fine mesh). Kemudian [2] dengan membandingkan mesh dengan 1000K (coarse mesh), 1400K (medium mesh) dan 2000K (fine mesh).

Kapal tipe planing yaitu memiliki gaya hidrostatik yang lebih kecil daripada gaya hidrodinamiknya [3]. Prediksi hambatan kapal bertipe planing hull lebih rumit dibandingkan kapal dengan tipe displacement hull, karena pada tipe planing hull memiliki gerakan trim (rolling sumbu y) dan heave (translasi sumbu $\mathrm{z}$ ) yang mempengaruhi nilai hambatan total. Oleh karena itu, simulasi kapal tipe planing cukup rumit sehingga masih terjadi ketidakakuratan hasil pada Froude number tinggi. Beberapa penelitian sebelumnya yang melakukan simulasi kapal tipe planing hull yaitu [4] melakukan simulasi kapal planing dengan metode overset mesh dan menerapkan metode phase replacement dalam mengurangi NVP (Numerical Ventilation Problem. Cara lain untuk mengurangi NVP dilakukan dengan mesh refinement [5]. Selanjutnya penelitian mengenai prediksi hambatan pada kapal planing hull [6]. Pada penelitian tersebut dilakukan pada kondisi perairan bergelombang dengan menggunakan metode moving grid dan tipe trimmed mesh. Penelitian lainnya tentang optimasi step hull pada kapal planing hull dengan menggunakan tipe mesh tetrahedral [7]. Pada penelitian ini dilakukan 2 validasi yaitu terhadap eksperimen dan mesh independency. Studi tentang verifikasi bentuk lambung Fridsma hull form dengan metode overset grid dan tipe mesh trimmed dilakukan untuk memastikan bahwa CFD dapat memprediksi hambatan pada kapal cepat [8,9]. Penelitian tentang kapal planing dengan lambung deep- $V$ pada kondisi air tenang dilakukan dengan menggunakan bentuk kapal yang lebih rumit [10]. Penelitian tersebut menggunakan metode mesh moving dan tipe mesh trimmed dengan validasi hasil menggunakan data eksperimen.

Pada tahun 1969, Gerald Fridsma melakukan eksperimen kapal dengan tipe planing hull pada kondisi air tenang (smooth-water) dan bergelombang (rough-water). Hull yang digunakan dalam eksperimen dikenal sebagai Fridsma hull form. Selain 2 kondisi perairan, ada beberapa variabel yang digunakan dalam penelitiannya seperti panjang hull (lambung), displacement, LCG (Longitudinal Center of Gravity), sudut dead-rise, kecepatan dan beberapa variabel lainnya [11].

Corresponding Author: samuel@ft.undip.ac.id

Received on: November 2020

Accepted on: March 2021 
Mesh secara umum dibagi menjadi 2 tipe yaitu mesh terstruktur dan mesh tidak terstruktur. Mesh terstruktur berbentuk segi empat sedangkan mesh tidak terstruktur berbentuk polyhedral dan tetrahedral [12]. Setiap tipe mesh memiliki kelebihan dan kekurangannya masing-masing, baik dalam lama waktu create mesh, lama waktu komputasi hingga keakuratan hasilnya.

Berdasarkan fakta penelitian diatas, maka untuk memprediksi hambatan kapal cepat diperlukan strategi khusus untuk memperbaiki hasil simulasi. Sehingga pada penelitian ini akan dilakukan pendekatan menggunakan bentuk mesh dan kerapatan mesh. Pendekatan menggunakan metode tersebut diharapkan akan memperbaiki hasil akurasi CFD terhadap eksperimen.

\section{METODE}

Penelitian ini dilakukan dengan menggunakan metode komputasi yang kita kenal dengan CFD (Computational Fluid Dynamic). Metode untuk memperbaiki tingkat akurasi dengan mencari mesh independency untuk menganalisis hambatan kapal, sehingga tidak akan mengalami perubahan sejalan dengan penambahan jumlah mesh. Selanjutnya menganalisa hasil simulasi dengan tipe mesh yang berbeda beda pada overset box. Pembagian metode dalam penelitian ini meliputi objek penelitian yang berupa data eksperimen, kemudian setup dari metode numerik yang digunakan dan variabel mesh yang digunakan.

\subsection{Objek Penelitian}

Studi ini menggunakan data eksperimen dari Fridsma pada tahun 1969 sebagai validasi terhadap eksperimen. Data eksperimen yang digunakan yaitu lambung uji coba pada keadaan air tenang yang dapat dilihat pada Tabel 1 dan Gambar 1. Pada studi ini digunakan 3 variasi kecepatan dengan Froude number 1.19, 1.49 dan 1.79 .

Tabel 1: Data Eksperimen Fridsma [11]

\begin{tabular}{l|l|l}
\hline Parameter & Unit & Nilai \\
\hline $\mathrm{L} / \mathrm{B}$ & - & 5 \\
\hline $\mathrm{L}$ & $\mathrm{m}$ & 1.143 \\
\hline $\mathrm{B}$ & $\mathrm{m}$ & 0.229 \\
\hline $\mathrm{T}_{\mathrm{AP}}$ & $\mathrm{m}$ & 0.081 \\
\hline LCG dari AP & $\mathrm{m}$ & 0.457 \\
\hline VCG dari keel & $\mathrm{m}$ & 0.067 \\
\hline$\tau_{\mathrm{o}}$ & Derajad & 1.569 \\
\hline $\mathrm{B}$ & Derajad & 20 \\
\hline$\Delta$ & Kg & 10.890 \\
\hline $\mathrm{I}_{\mathrm{yy}}=\mathrm{I}_{\mathrm{zz}}$ & Kg.m ${ }^{2}$ & 0.235 \\
\hline & &
\end{tabular}
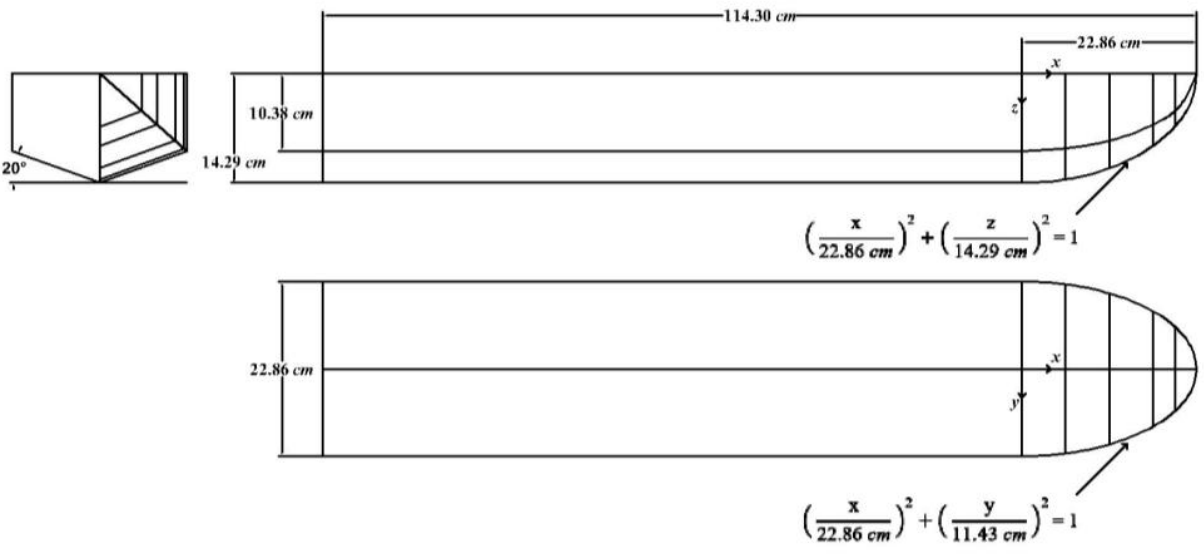

Gambar 1: Fridsma hull form [11] 


\subsection{Metode Numerik}

RANS (Reynolds-Averaged Navier-Stokes) merupakan metode pemecahan masalah berdasarkan hukum konservasi massa dan momentum. Persamaan RANS banyak digunakan dalam pemecahan masalah hidrodinamik dengan aliran incompressible yang ditunjukkan dalam persamaan 1 dan 2.

$$
\begin{aligned}
& \nabla \cdot U=0 \\
& \rho \frac{\partial U}{\partial t}=-\nabla P+\mu \Delta U+\nabla \cdot T_{R e}+S_{M}
\end{aligned}
$$

Dimana $\nabla$ adalah volume, $U$ adalah vektor kecepatan rata-rata, $\rho$ adalah massa jenis, $t$ adalah waktu, $P$ adalah bidang tekan rata-rata, $\mu$ adalah viskositas dinamis, $T_{R e}$ adalah tensor dari Reynolds stress, $\Delta$ adalah displacement dan $S_{M}$ adalah vektor sumber momentum. Komponen $T_{R e}$ dihitung dengan menggunakan model turbulensi yang dipilih, sesuai dengan hipotesis Boussinesq pada persamaan 3.

$$
\tau_{i j}^{R e}=\mu_{t}\left(\frac{\partial U_{i}}{\partial x_{j}}+\frac{\partial U_{j}}{\partial x_{i}}\right)-\frac{2}{3} \rho k \delta_{i j}
$$

Dimana $\mu_{\mathrm{t}}$ adalah viskositas turbulen, $\mathrm{k}$ adalah energi kinetik turbulen. Ada banyak model turbulensi yang dapat digunakan untuk menutup masalah hidrodinamik dalam metode RANS. Secara khusus dalam bidang hidrodinamik, model turbulensi yang banyak digunakan adalah model dua persamaan tersebut, seperti SST k- $\omega$ dan k-e.

Wall function $(y+)$ digunakan untuk mengurangi ketidakuratan perhitungan. Nilai $y+$ antara $45-60$ untuk mendapatkan hasil yang akurat [13], sedangkan pada penelitian lain menyarankan nilai $y+$ berada pada rentang 50-150 [14]. Pada penelitian ini digunakan y+ seperti pada Gambar 2. Perhitungan nilai $y+$ menurut ITTC [15] yang ditunjukkan pada persamaan 4.

$$
\frac{\mathrm{y}}{\mathrm{L}}=\frac{\mathrm{y}^{+}}{\mathrm{R}_{\mathrm{e}} \sqrt{\frac{\mathrm{C}_{\mathrm{f}}}{2}}}
$$

Dimana y adalah tebal layer pertama, $\mathrm{L}$ adalah panjang objek, $\mathrm{R}_{\mathrm{e}}$ adalah Reynold number dan $\mathrm{C}_{\mathrm{f}}$ adalah estimasi dari koefisien gesek permukaan objek.

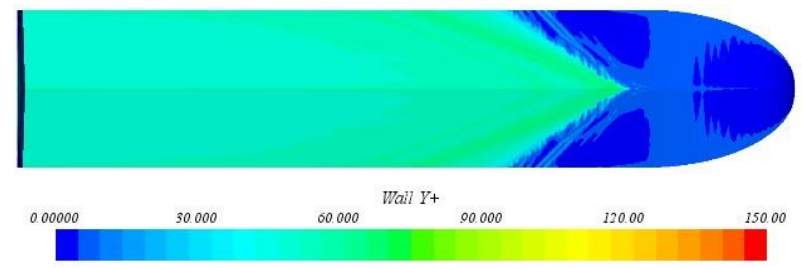

Gambar 2: Visualisasi $y+$ pada Fr 1.79

Time-step digunakan dalam simulasi aliran unsteady. Time step merupakan interval periode untuk setiap perhitungan iterasi. Untuk menentukan time-step pada perhitungan CFD tergantung pada kecepatan kapal. Semakin cepat kecepatan kapal, semakin kecil nilai time-step dan semakin lama waktu penyelesaiannya. Penentuan time-step yang direkomendasikan oleh ITTC [15] terdapat pada persamaan 5. Dengan L sebagai panjang kapal dan V sebagai kecepatan kapal.

$$
\Delta \mathrm{t} \text { ITTC }=0.005 \sim 0.01 \frac{\mathrm{L}}{\mathrm{V}}
$$

\subsection{Meshing}

Metode overset mesh membagi dua geometri dari virtual towing tank yaitu background sebagai donor dan overset sebagai acceptor. Dimensi yang digunakan dalam penelitian ini seperti tertera pada Tabel 2 dan Gambar 3 yang mengikuti rekomendasi ITTC. Dengan L adalah panjang kapal, $\mathrm{H}$ adalah tinggi kapal, dan B adalah lebar kapal. 
Tabel 2: Dimensi towing tank

\begin{tabular}{l|l|l}
\hline Parameter & Background & Overset \\
\hline \multirow{2}{*}{ Panjang $(\mathrm{m})$} & 1L dari FP & $0.25 \mathrm{~L}$ dari FP \\
\cline { 2 - 3 } & $2.5 \mathrm{~L}$ dari AP & $0.25 \mathrm{~L}$ dari AP \\
\hline \multirow{2}{*}{ Tinggi $(\mathrm{m})$} & 1L dari deck & $0.75 \mathrm{H}$ dari deck \\
\cline { 2 - 3 } & 2L dari keel & $0.75 \mathrm{H}$ dari keel \\
\hline Lebar $(\mathrm{m})$ & $1.5 \mathrm{~L}$ dari symmetry & $0.5 \mathrm{~B}$ dari symmetry \\
\hline
\end{tabular}

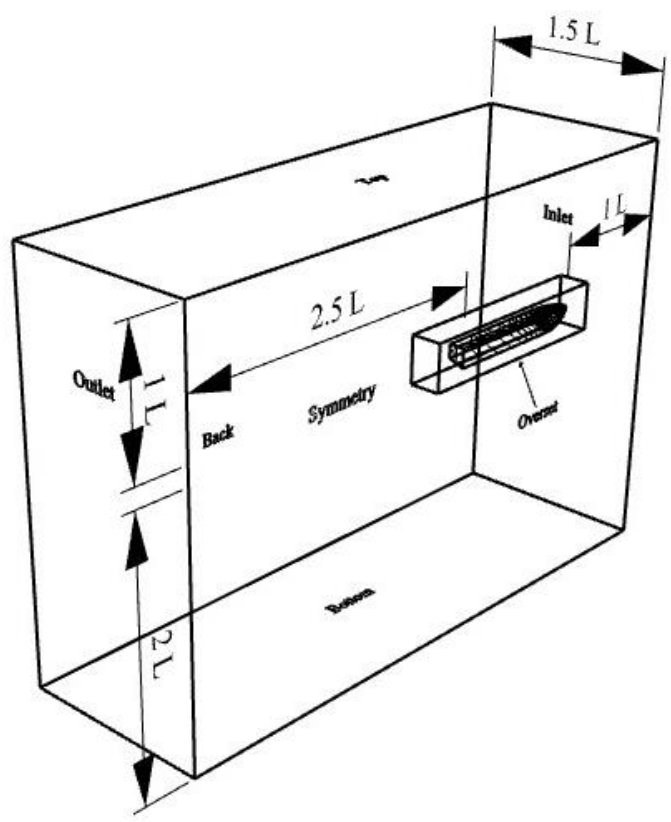

Gambar 3: Dimensi dan surface domain

Kerapatan mesh difokuskan pada objek dan permukaan air agar hasil tetap akurat dalam waktu komputasi yang relatif lebih cepat. Mesh refinement dilakukan dengan menggunakan metode anisotropic mesh untuk memfokuskan pada ordinat $\mathrm{x}, \mathrm{y}$, atau z. Pada simulasi ini kerapatan mesh dibagi menjadi beberapa bagian untuk mendapatkan mesh independency seperti pada Tabel 3 dan Gambar 4. Jumlah total elemen dari variasi kerapatan mesh dapat dilihat pada Tabel 4.

Tabel 3: Kerapatan mesh

\begin{tabular}{l|l}
\hline Nama bagian & Dimensi mesh \\
\hline Far Field & $0.7874 \mathrm{~L}$ \\
\hline Block 1 & $0.0492 \mathrm{~L}$ \\
\hline Overlap & $0.0123 \mathrm{~L}$ \\
\hline Overset & $0.0230 \mathrm{~L}$ \\
\hline Free Surface & $0.0062 \mathrm{~L}$ \\
\hline Hull & \\
\hline - Very Coarse & $0.0062 \mathrm{~L}$ \\
\hline - Coarse & $0.0031 \mathrm{~L}$ \\
\hline - Medium & $0.0025 \mathrm{~L}$ \\
\hline - Fine & $0.0015 \mathrm{~L}$ \\
\hline - Very Fine & $0.0014 \mathrm{~L}$ \\
\hline
\end{tabular}


Tabel 4: Jumlah elemen mesh

\begin{tabular}{l|c}
\hline Kualitas mesh & Jumlah total elemen \\
\hline Very Coarse & 487,054 \\
\hline Coarse & 897,038 \\
\hline Medium & $1,440,767$ \\
\hline Fine & $2,331,333$ \\
\hline Very Fine & $2,990,983$ \\
\hline
\end{tabular}
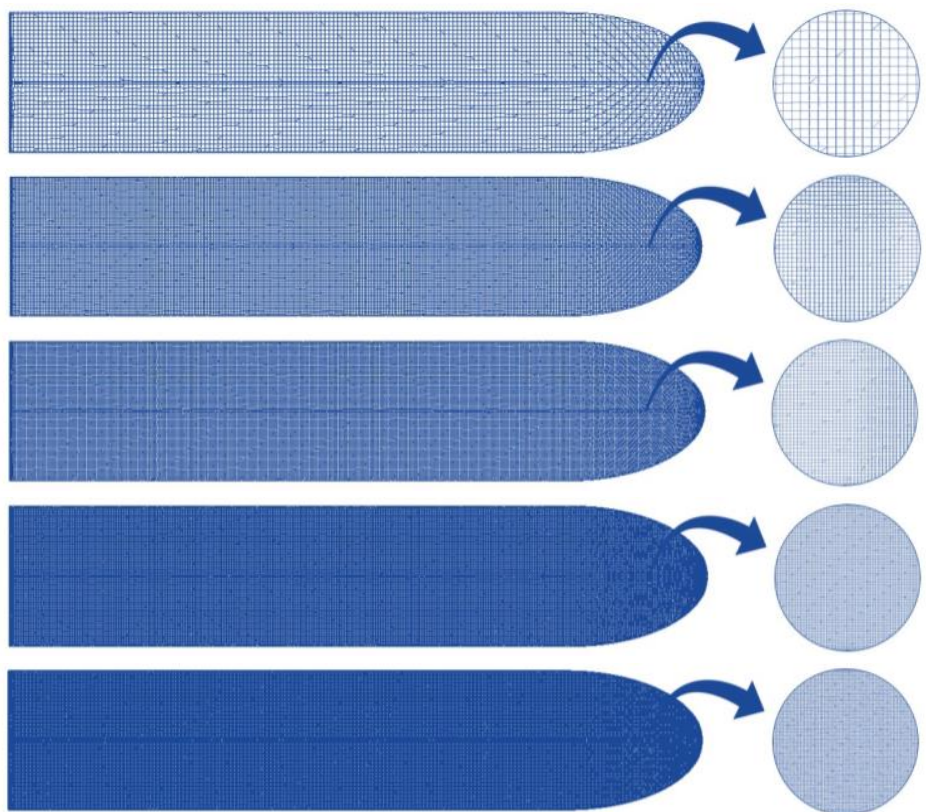

Gambar 4: Visualisasi kerapatan mesh secara berurutan dari atas kebawah : Very Coarse, Coarse, Medium, Fine dan Very Fine

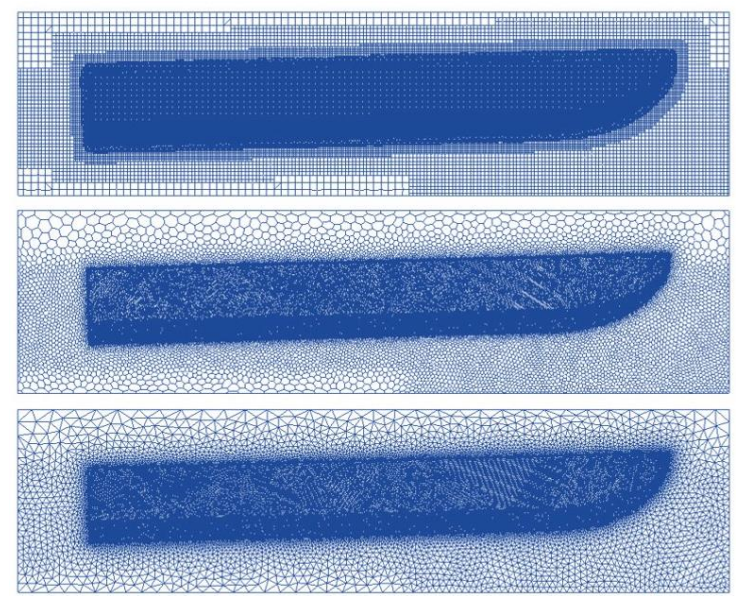

Gambar 5: Visualisasi tipe mesh, Trimmed (atas), Polyhedral (tengah) dan Tetrahedral (bawah)

Kemudian dibandingkan antara mesh terstruktur dengan tidak terstruktur pada bagian overset box. Hal ini mengikuti rekomendasi dari Mancini pada penelitiannya. Hasil penelitiannya yaitu mesh tidak terstruktur lebih baik dari mesh terstruktur dalam keakuratan hasil [16]. Namun sebagian besar penelitian menggunakan tipe trimmed mesh pada kedua geometri (background dan overset box) dan menunjukkan prediksi yang baik. Sehingga pada penelitian ini akan dibandingkan 2 tipe mesh, yaitu mesh tidak terstruktur (Polyhedral dan Tetrahedral) dan mesh terstruktur (Trimmed). Pada perbandingan tipe mesh, jumlah mesh dibatasi pada angka 2,300K elemen (fine mesh), sehingga membebaskan dimensi mesh (Polyhedral dan Tetrahedral). Dimensi mesh pada hull dan jumlah total elemen pada masing-masing variasi tertera pada Tabel 5. 
Sedangkan untuk visualisasi tipe mesh dapat dilihat pada Gambar 5.

Tabel 5: Parameter perbandingan tipe mesh

\begin{tabular}{l|l|l}
\hline Tipe mesh & Dimensi mesh (hull) & Jumlah total elemen \\
\hline Trimmed & $0.0015 \mathrm{~L}$ & $2,331,333$ \\
\hline Polyhedral & $0.0016 \mathrm{~L}$ & $2,313,363$ \\
\hline Tetrahedral & $0.0028 \mathrm{~L}$ & $2,330,155$ \\
\hline
\end{tabular}

\section{HASIL DAN DISKUSI}

Pada penelitian ini dilakukan mesh independency untuk memastikan hasil sudah stabil/dependen. Kemudian dilakukan variasi tipe mesh pada bagian overset box pada rentang mesh yang telah stabil/dependen.

\subsection{Mesh Independency}
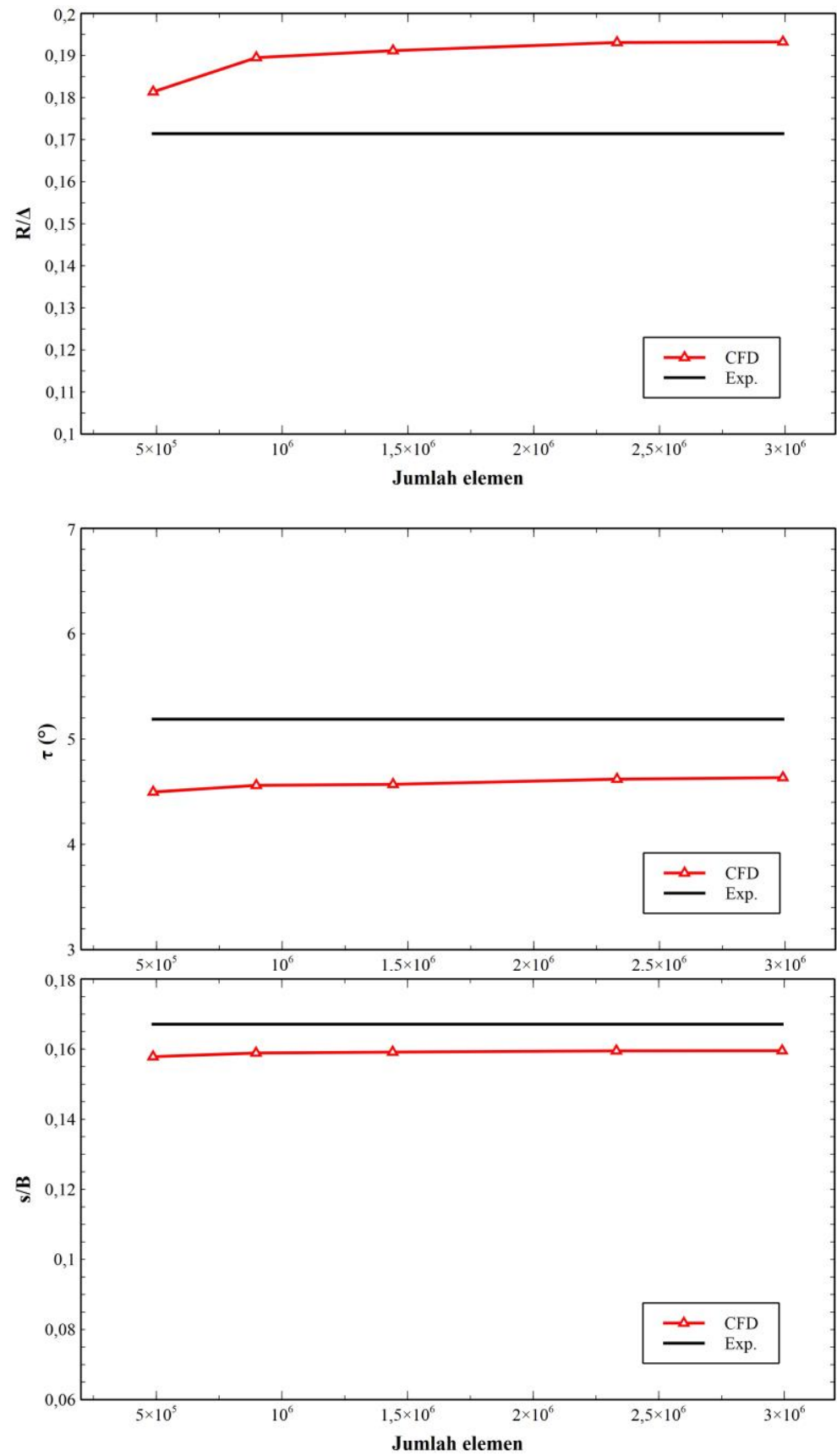

Gambar 6: Grafik mesh independency dari hambatan, trim dan heave 
Mesh independency divisualisasikan dengan perbandingan nilai hambatan, trim dan heave terhadap jumlah elemen seperti pada Gambar 6. Simulasi dilakukan pada Fr 1.79 dengan 5 variasi jumlah elemen. Pada komponen sumbu $\mathrm{y}$, hambatan digambarkan dengan non dimensional unit $\mathrm{R} / \Delta$, dengan $\mathrm{R}$ sebagai hambatan (N) dan $\Delta$ sebagai berat kapal $(\mathrm{N})$. Trim digambarkan dalam unit derajad (o). Heave dengan satuan non dimensional s/B dengan s sebagai displacement antara titik awal dan akhir pada sumbu z kapal (m) dan B sebagai lebar kapal (m). Sedangkan untuk komponen sumbu x yaitu variasi jumlah elemen dengan kualitas very coarse, coarse, medium, fine dan very fine.

Berdasarkan grafik hambatan, mesh sudah konvergen pada jumlah elemen 2,300K. Namun masih memiliki nilai error terhadap hasil eksperimen sebesar $11.2 \%$. Berbanding terbalik jika dibandingkan hasil dari very coarse dengan error sebesar 5.5\%. Hal tersebut dikarenakan terdapat aliran fraksi bukan air maupun udara yang melalui hull kapal seperti terlihat pada visualisasi Wetted Surface Area (WSA) (gambar 7). Sehingga hambatan yang terhitung akan lebih kecil karena massa jenis dianggap kecil (aliran campuran). Keadaan ini sama seperti hasil yang ditunjukkan pada penelitiannya Wheeler et al. [1] dan Mousaviraad et al. yang melakukan [17] simulasi numerik dengan Fridsma hull form. Penelitiannya Wheeler mengalami error sebesar $17.26 \%$ dan penelitiannya Mousaviraad sebesar $20.99 \%$ pda Fr 1.79 .

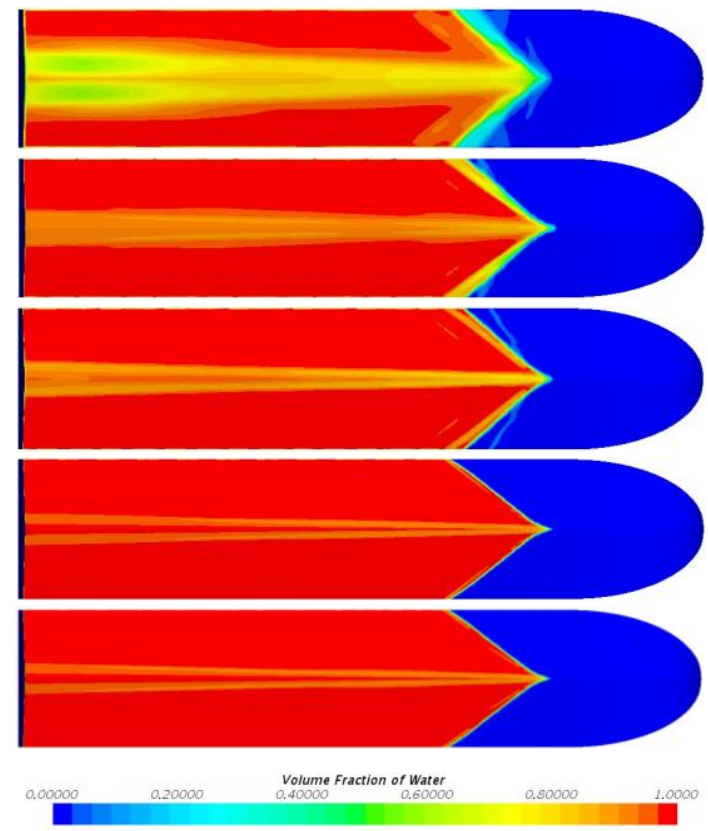

Gambar 7: Visualisasi WSA pada Fr 1.79 secara berurutan dari atas kebawah : Very Coarse, Coarse, Medium, Fine dan Very Fine

Hasil trim dan heave sudah konvergen pada jumlah elemen 2,300K. Nilai error trim hasil komputasi terhadap ekperimen sebesar 11.9-12.3\%. Sedangkan nilai error heave hasil komputasi terhadap eksperimen sebesar $4.7 \%$. Hasil ini cukup baik dimana memodelkan simulasi kapal tipe planing cukup kompleks karena membutuhkan 2 DOF. Selain itu sering terjadi numerical ventilation (NV) pada kecepatan tinggi. Hal tersebut mengurangi keakuratan hasil simulasi.

\subsection{Perbandingan Tipe Mesh}

Perbandingan tipe mesh dilakukan pada jumlah mesh yang menunjukkan nilai yang konvergen. Sehingga untuk memvariasi tipe mesh, masing-masing tipe mesh dibatasi dengan jumlah mesh pada angka 2,300K elemen. Sehingga ukuran mesh dibebaskan dengan refinement yang masih sama pada setiap setupnya. Pada perbandingan tipe mesh digunakan 3 variasi kecepatan yaitu pada Fr 1.19, 1.49 dan 1.79.

Dari grafik hambatan pada Gambar 8, mesh dengan tipe polyhedral menunjukkan hasil yang paling baik dibandingkan tipe mesh trimmed dan tetrahedral. Memiliki selisih terhadap hasil eksperimen sebesar 6.1-8.6\%. Sedangkan tipe trimmed memiliki selisih terhadap hasil eksperimen sebesar 8.2-11.2\%. Terjadi error yang cukup besar pada simulasi dengan tipe mesh tetrahedral, yaitu sebesar 1.5-21.7\%. Hal tersebut terjadi karena terjadi NV yang cukup parah pada daerah yang seharusnya daerah basah (WSA). Hal tersebut 
dapat dilihat melalui visualisasi WSA pada Gambar 9.
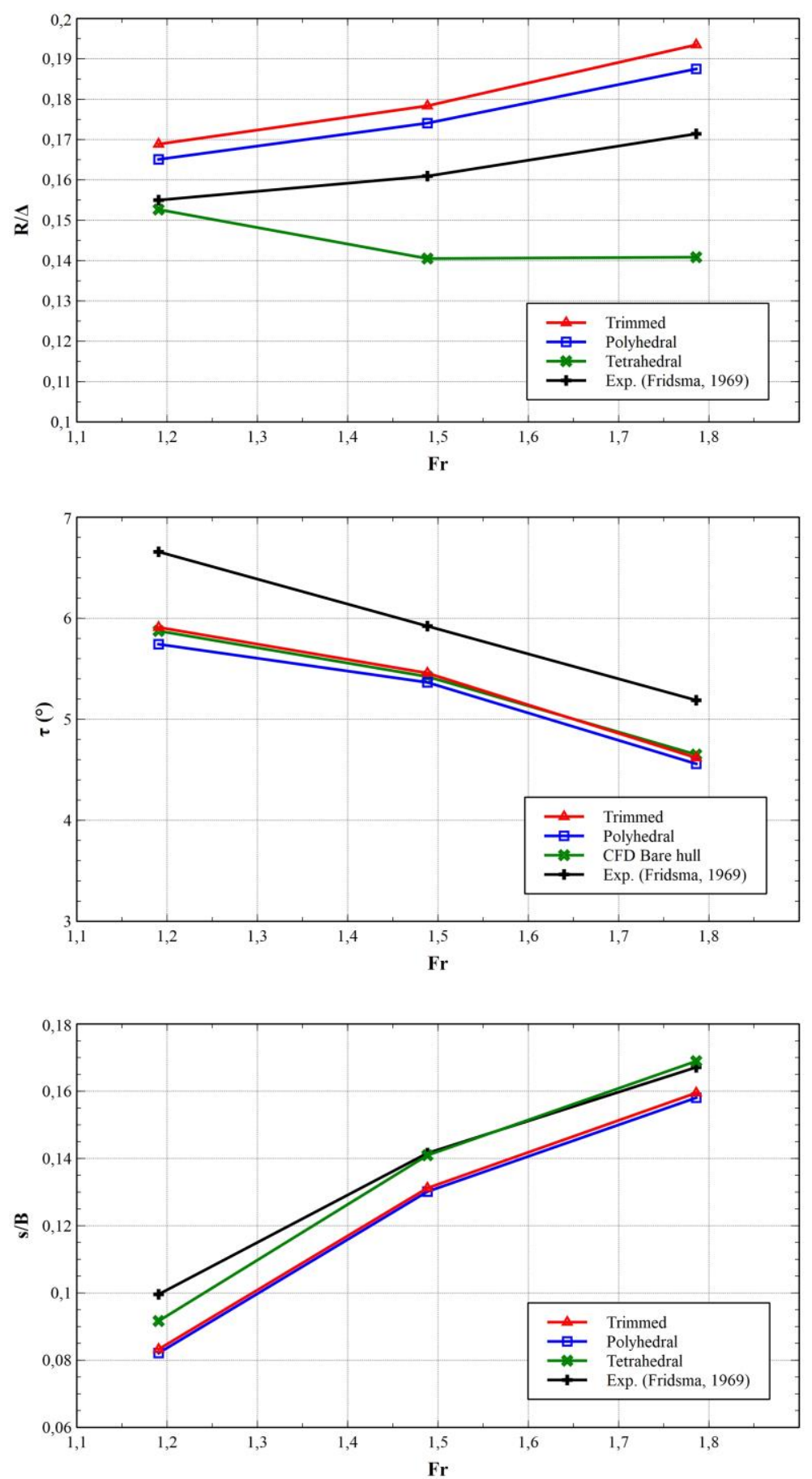

Gambar 8: Grafik hambatan, trim dan heave dari variasi tipe mesh

Dari grafik trim pada Gambar 8, mesh dengan tipe trimmed dan tetrahedral cukup baik dalam memprediksi dengan selisih sebesar 11.5-13.3\% terhadap hasil eksperimen. Sedangkan mesh dengan tipe polyhedral memiliki selisih sedikit lebih besar yaitu 13.8-15.9\%. Sedangkan pada grafik heave, hasil baik ditunjukkan oleh mesh dengan tipe tetrahedral dengan selisih hasil terhadap eksperimen sebesar 1.1-8.8\%. Kemudian diikuti dengan tipe mesh trimmed dan polyhedral dengan selisih terhadap eksperimen sebesar 4.8$21.3 \%$. 


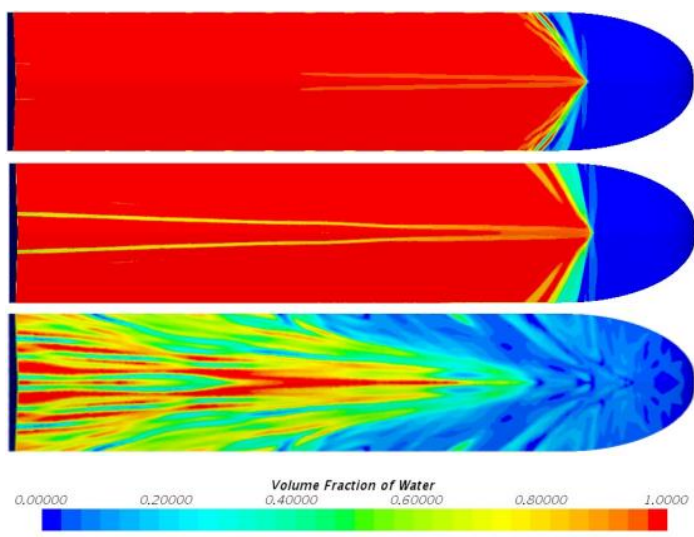

Gambar 9: Visualisasi WSA pada Fr 1.19 secara berurutan dari atas kebawah : Trimmed, Polyhedral dan Tetrahedral

Perbandingan lama waktu create mesh dibagi menjadi dua kondisi yaitu ketika jumlah mesh sama seperti pada yang digunakan pada penelitian ini dan ketika ukuran mesh yang sama. Pada kondisi jumlah mesh yang disamakan, mesh tipe tetrahedral lebih cepat dibandingkan dua tipe mesh lainnya. Sedangkan pada kondisi ukuran mesh yang disamakan, tipe trimmed lebih cepat dibandingkan dua tipe mesh lainnya yang dapat dilihat pada Tabel 6.

Tabel 6: Perbandingan waktu create mesh pada setiap tipe mesh

\begin{tabular}{l|l|l}
\hline \multirow{2}{*}{ Tipe mesh } & \multicolumn{2}{|l}{ Lama create mesh (s) } \\
\cline { 2 - 3 } & Jumlah mesh sama & Ukuran mesh sama \\
\hline Trimmed & 473 & 317 \\
\hline Polyhedral & 1481 & 1481 \\
\hline Tetrahedral & 181 & 848 \\
\hline
\end{tabular}

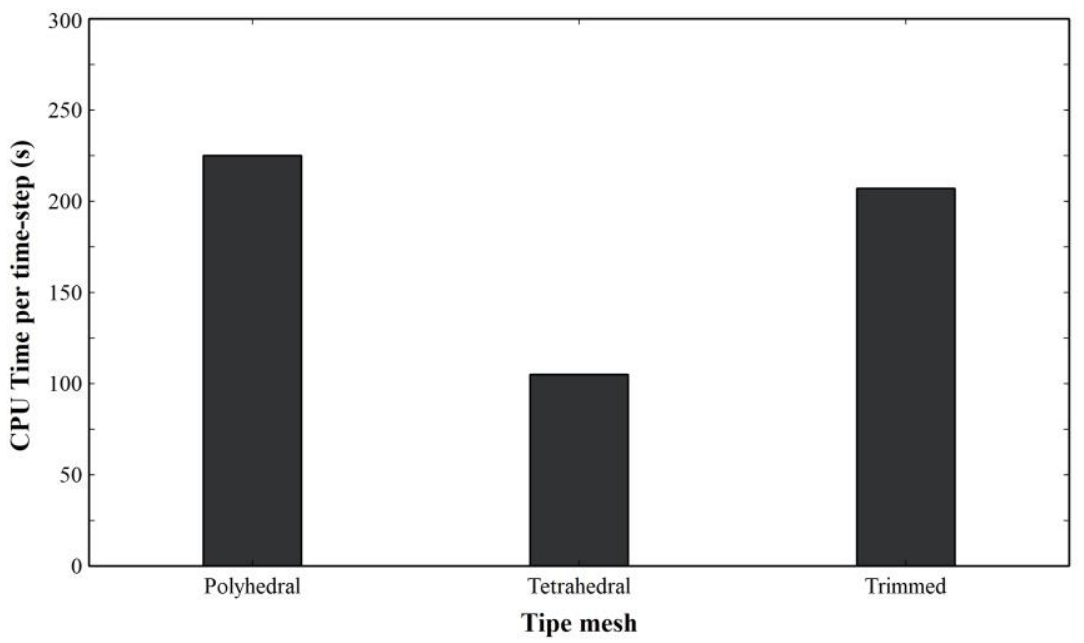

Gambar 10: Grafik perbandingan waktu komputasi pada tipe mesh Trimmed, Polyhedral dan Tetrahedral

Gambar 10 merupakan perbandingan rata-rata lama waktu perhitungan CPU per time-step pada tipe mesh trimmed, polyhedral dan tetrahedral. Dari grafik, tipe mesh tetrahedral memiliki waktu komputasi yang relatif lebih cepat dibanding dengan kedua mesh lainnya. Hal tersebut karena kerapatan mesh (base mesh) tipe tetrahedral lebih besar dibandingkan tipe trimmed dan polyhedral. Sedangkan trimmed dan polyhedral memiliki waktu komputasi yang relatif sama. Karena kerapatan mesh (bese mesh) kedua tipe ini hampir sama. 


\section{KESIMPULAN}

Mesh dependen pada jumlah mesh $2300 \mathrm{~K}$ dengan ditunjukkan hasil hambatan, trim dan heave yang stabil. Tipe mesh trimmed lebih efisien karena pada jumlah mesh yang sama, ukuran mesh (base size) lebih kecil dari 2 tipe lainnya, sehingga hasil akan lebih akurat. Tidak terjadi NV pada mesh tipe trimmed, namun terjadi NV cukup besar pada mesh tipe tetrahedral, sehingga mempengaruhi hasil prediksi. Tipe polyhedral sama baiknya dengan trimmed, namun tidak lebih efisien pada jumlah dan waktu komputasi, serta terjadi NV.

\section{PERNYATAAN TERIMAKASIH}

Penulis mengucapan terima kasih kepada Laboraturium Komputer \& Desain Kapal Universitas Diponegoro atas dukungan dalam melakukan penelitian ini.

\section{DAFTAR PUSTAKA}

[1] WHEELER, M. P., MATVEEV, K. I., XING, T., "Validation Study of Compact Planing Hulls at PrePlaning Speeds," in ASME 2018 5th Joint US-European Fluids Engineering Summer Conference, 2018, pp. $1-8$.

[2] IACONO, M., Hydrodynamics of Planing Hull By CFD, vol. 08, p. 202, 2015.

[3] FALTINSEN, O. M., Hydrodynamics of High-Speed Marine Vehicles. New York: Cambridge University Press, 2005.

[4] FATHUDDIIN, A. SAMUEL, KIRYANTO, WIDYANDARI, A. "Prediksi Hambatan Kapal dengan Menggunakan Metode Overset Mesh pada Kapal Planing Hull,” Jurnal Rekayasa Hijau, vol. 4, no. 1, pp. 24-34, 2020.

[5] SAMUEL, KIM, D. J., FATHUDDIIN, A. ZAKKI, A. F., "A Numerical Ventilation Problem on Fridsma hull form using an overset grid system," in 6th International E-Conference on Industrial, Mechanical, Electrical and Chemical Engineering (ICIMECE 2020), 2020.

[6] SAMUEL, TRIMULYONO, A. and SANTOSA, A. W. B. "Simulasi CFD pada Kapal Planing Hull," KAPAL : Jurnal Ilmu Pengetahuan \&Teknologi Kelautan, vol. 16, no. 3, pp. 123-128, 2019.

[7] NOURGHASEMI, H., BAKHTIARI, M., GHASSEMI, H., "Numerical study of step forward swept angle effects on the hydrodynamic performance of a planing hull," Scientific Journals of the Maritime University of Szczecin, vol. 51 (123), pp. 35-42, 2017.

[8] SUKAS, O. F., CAKICI, F., GOKCE, M. K., "Numerical Simulation of Fridsma Hull Using Overset Grid System," in 19th Numerical Towing Tank Symposium, 2016.

[9] BRIZZOLARA, S. and VILLA, D., "CFD Simulation of Planing Hull," in Seventh International Conference On High-Performance Marine Vehicles, 2010.

[10] SAMUEL, JOKOSISWORO, S., IQBAL, M., MANIK, P., RINDO, G., "Verifikasi Deep - V Planing Hull Menggunakan Finite Volume Method Pada Kondisi Air Tenang," TEKNIK, vol. 41, no. 2, pp. 126-133, 2020.

[11] FRIDSMA, G., A Systematic Study of The Rough-water Performance of Planning Boat, New Jersey, 1969.

[12] CD-ADAPCO, User guide STAR-CCM 13.02.011-R8. 2017.

[13] AVCI, A. G. and BARLAS, B., "An experimental and numerical study of a high speed planing craft with full-scale validation," Journal of Marine Science and Technology, vol. 26, no. 5, pp. 617-628, 2018.

[14] LOTFI, P., ASHRAFIZAADEH, M. and ESFAHAN, R. K., "Numerical investigation of a stepped planing hull in calm water," Ocean Engineering, vol. 94, pp. 103-110, 2015.

[15] ITTC, Practical Guidelines for Ship CFD Applications, 2011.

[16] MANCINI, S., The Problem of Verification and Validation Processes of CFD Simulations of Planing Hulls, Università Degli Studi Di Napoli Federico II, 2015.

[17] MOUSAVIRAAD, S. M., WANG, Z., STERN, F., "URANS studies of hydrodynamic performance and slamming loads on high-speed planing hulls in calm water and waves for deep and shallow conditions," Applied Ocean Research, vol. 51, pp. 222-240, 2015. 